\title{
"Why don't you like me the way I am? I'm not a genius": A Mistakable Understanding of a Child Prodigy in Amy Tan's Two Kinds, the Symbolic Crisis of Identity in the Specific Contexts of the American Dream.
}

\author{
Akm Aminur Rashid \\ English Department, Dalarna University, Falun, Sweden
}

\begin{abstract}
In this paper I put a critical reflection on a symbolic crisis of identity found in Amy Tan's Two Kinds in which the narrator, Jing-mei narrates her conflict with her mother with regard to Jing-mei's being a prodigy. The nature of this work is a critical critique of Mrs. Woo's intention to make her daughter, Jing-mei Woo thriving on the chosen identity goals. The tension state comes into the plot, when Mrs. Woo's chosen identity goals meet interruption from her daughter's side because her daughter reflects on free will while her mother expects typical Chinese obedience from her daughter. Jing-mei has to go through several tests by her mother; but ultimately fails. The mother-daughter relationship reaches its climax, when in the struggle mother asks daughter questions of identity; and daughter rebels against mother and her unreasonable pathways. The story has actually a poignant failure of both mother-daughter relationship; relevant indicators of identity; and a lack of effective communication between mother and daughter regarding to a self-defining, or a non-self defining goal. However, the American renaissance that is said to bring pathways to success has its close link with the identity politics in which identity is performed, tested, and changed.
\end{abstract}

Keywords: American Dream, Opportunity, Prodigy, Failure, Death.

\section{Introduction}

Human history meets a greater number of threats that appear as being concrete- famine, war, flood, cyclone, mass-killing and the like. In the post-material era as we are moving in now, much of the threats originated from non-materialistic factors is intensifying our living environment. In particular, one of the most concerned aspect of non-materialistic factors is 'assuming/constructing individual identity' which is threatened by expansion of the post-material interests; and the emerges of transatlantic businesses. In fact, in the sphere of globalized immigration, it happens that immigrants have to observe; and also to experience new phenomenon, culture, language, mounting complexity, alien to comprehend and cope with. Such are the ready environments that produce fears; and form sometimes no solutions, or knowledge to act upon so easily. It is a new code of life in which individual identities meet collective identities; and there are regular constructions of selfhood available even though sometimes, or more frequently, those constructions constitute a thought-world coupled with a thought-style. For instance, thought-world consists of ways of thinking while thought-style corresponds to the selfhood to act accordingly. America, in this regard, becomes, in the most part of a human's life, an influential concept after the year of 1776 with the advent of the American Renaissance. After liberation from the British power, America tends to resound the emergence of a unique 'Enlightened Thought and Practice' that leads every American's self to assume a conscious identity, that is to say, the essence of reflexive thought to have a better life. Such essence of reflexive thought, as Kenneth J. Gergen says, is "for philosophers such as Descartes, Locke and Kant, reflexive thought (reason gaining knowledge of reasoning itself) was a means toward a morality, personal integrity, and a coherent life" (Gergen 2007, p. 149). So as studied, Amy Tan's Two kinds starts with this same spirit of reflexive thought of Mrs. Woo, who projects her long cherished but unfulfilled desires onto her daughter, Jing-mei, who nothing but unfortunately fails to track her mother's tailored way to success. Thus the relationship takes on a powerful expose on the problems of identity surrounding Mrs. Woo's expectations from her daughter and Jing-mei's negative response to her mother's unreasonable expectations. Mrs. Woo comes out of the Chinese Communist Revolution whereas Jing-mei Woo is born in America. So, there are two cultures like Mrs. Woo's Chinese ancestry and Jing-mei Woo's being Americanized meet, and collide together.

\subsection{The Aim/Contribution of the Paper}

I am not in this paper going to invoke the Chinese Communist revolution in its connection to Mrs. Woo's failure and anxieties in the past. I do rather want to address those relevant issues on identity that are precisely placed in the novel's plot by Amy Tan in fact. Two Kinds has two main characters - Mrs. Woo and Jing-mei Woo, who reflect on generations of two different kinds; and reflexive thought of two different kinds at 
the same time. The tension arises when Mrs. Woo's belief in American dream [renaissance] meets Jing-mei's Woo's conscious reason; meaning Mrs. Woo thinks that her daughter can perform as being a prodigy through hard work, while Jing-mei Woo cannot show promise in her mother's chosen areas. E. D. Huntley speaks:

The apparent folly of Mrs. Woo's aspirations for her daughter can be learnt from her dogmatic belief that America is the Land of Opportunity. She places unreasonable expectations on the shoulders of her young, tender daughter. While the mother may not exactly know where her daughter's prodigal talents lie, she is nevertheless adamant that her daughter is destined for greatness, by virtue of having been born in America.

First, Mrs. Woo tries to model her daughter into a famous actress, but that fails abjectly. Then she puts Jing-mei through general knowledge tests. Young Jing-mei doesn't show promise in this area, either. Finally, her mother hits upon the answer: Jing-mei will be a piano virtuoso. This time too, the decision been arrived without rationale and conviction. (Huntley, 1998)

Another fact that I also studied as being more important a perspective to ponder about is that the mother-daughter relationship also secure two different domains of entities. For instance, the psychological interior of Mrs. Woo's self is shaped by her belief in the discourse of American dream's promise of success. On the other hand, since Jing-mei Woo is born in modern America; the country's age of enlightenment gives her a cultural construction, that is, agentive reason. So, in my view the historic context between mother-daughter relationship functions as being 'self-employed' in each particular discourse. As being apparent in the text, the varying context of tradition [different awareness of historical contingency], Mrs. Woo reflects on, constitutes, in a significant way, an ontology based discourse to attain success. In Jing-mei Woo's case, the context of tradition, I mean her ways of thinking, is based on agentive reason as mentioned above. As being located in the American modernity, Jing-mei Woo's assumption of thought is structured with decolonizing ideas, that were ontologically referent for the pre-moderns. Mrs. Woo tries continually to bring out the prodigal talent in her daughter but she does not know where exactly her daughter's prodigal talents flank.

Jing-mei Woo says that " America was where all my mother's hopes lay. She had come to San Francisco in 1949 after losing everything in China: her mother and father, her home, her first husband, and two daughters, twin baby girls" (Tan 1992, p. 715). At first, Mrs. Woo tries Jing-mei Woo to be a model actress like Shirley Temple; but Jing-mei fails to show prodigal talent in that. Later, her mother puts her through general knowledge tests; Jing-mei shows no promise in this area as well. Finally, Jing-mei is expected as being a piano musician. Huntley says this is also decided by her mother without any rationale speculation and conviction (Huntley 1998). So, the concentration of the paper comes up with a core finding of the tension that finds way around a mistakable understanding of identity of Jing-mei Woo by her mother, who is of the opinion that America is the land of opportunity. The narrator says that " My mother believed you could be anything you wanted to be in America" (Tan 1992, p. 715). In fact, when mother's expectations, irrational though, could not meet her desired objectives in Jing-mei Woo, the vein of tension then turns to a symbolic crisis of identity. Amy Tan juxtaposes the intensified tension with the concept of the American dream. Thus promotes the problematized issues of creating identity to a more crucial level because the renaissance the dream brings in the American society is purely based on presumption of a good, coherent life.

The dream it all implies is of a good job, of decent home, of freedom, and of high life but the Americans had always to struggle in their life, little achievement was done though. In short, whatever the American renaissance, or the dream pursues for, it results in troubles, reports like Kansas City Federal Reserve Reports, Pathways to the middle class: Balancing personal and public responsibilities, Coming Apart say. The reports show that American dream costs much expensive; the dream it promises to the citizens and immigrants in America is empty inside. The dream in reality has addressed problems, and engaged people in collective selfdeception, reports also put. To speak simplifiedly, the dream evokes people to believe in its pathways and takes personal responsibility; but the pathways often have the lead to personal pitfalls. Tan's Two Kinds does not thoroughly rejects the possibilities of the American dream; but Mrs. Woo's excessive indulgence in thinking that her daughter would be whoever she wants be in America is potentially contradictory in nature of consideration. The American-born daughter, Jing-mei Woo has her own choice to carry on; but the Chinese mother leaves Jing-mei Woo with career prospects in that she gains no knowledge to cope with. However, at first I will here identify the gap that invites the symbolic crisis of identity by citing Alfred Remen Mele's 'Self-deception'. Mele argues in Real self-deception (1997) and Self-deception unmasked (2000):

In self-deception, the biasing - the selective focusing

upon certain kinds of evidence only, or the misinterpretation of certain

data - is motivated. Stated in ordinary terms, people believe things because

they want to believe them, and so they look for appropriate premises

that support the relevant belief (Mele, 1997, 2000).

In Mrs. Woo's case, it looks exact as Mele points out because Mrs. Woo supports the American dream's promise. The reason of her selective focus on such American renaissance, to a greater extent, has its root in her own loss and failure in the past. Now arriving in America, the given interpretations of the American dream 
might not be evidenced properly to her pragmatic daughter; but I vividly notice that Mrs. Woo is motivated by the promises the dream puts for the whole Americans.

\subsection{A Critical Critique of Amy Tan's Two Kinds}

Construction of "Identity and Subjectivity" is a very major concern to the people, who live in America as mere "immigrants". Like Amy Tan, many of the other American novelists deal with such people through the presentation of their own imaginative characters, who migrate from China, Korea and the like. The word "immigrant" has been a very widely quoted issue in these novels where the characters' identity is mixed, or doubled, and they cannot make out "Who they are" and "what they desire to be". Two kinds presents this concept of identity through Jing me, who wonders between her "being" and "becoming" and when failed, she cries at her mother "Why don't you like me the way I am?". She adds "I am not a genius!"(Tan 1989, p 719). Here the conflict starts between Jing-mei and her mother.

In fact, the characters, in these novels, feel a very complex psychological but emotional relationship, which is also complex in itself for each other. In Amy Tan's novel, "Two kinds" we find such kind of emotional yet complex relationship between Jing-mei and her mother. She has a Chinese background; but is born in America. The very opening line "My mother believed you could be anything you wanted to be in America" constitutes her (mother) own "subjectivity" that is brought into focus by herself. But, at the same time, this subjective emotion proves her identity as a "failure". Her mother is a failure in the sense that she has lost her "mother and father, her family home, her first husband, and two daughters, twin baby girls" (Tan 1989, p 715). Jing-mei realizes that her mother is over burdened with depression and utterly clings to Jing-me to make her well-known in future. Her mother remarks "You could open a restaurant"; "You could work for the government";"You could be best of anything" and so on (Tan 1989, p 715).

Thus, if it is scrutinized, the reader may see that Jing-me's mother wants to ignore her own failure status by her daughter's success. What she (mother) does to her daughter is "enforcement" not "inspiration" at all. Her mother suffers from unknowingness, that is, a sense of loss of identity. Thus, finally, she (mother) compensates her own loss trying to find a prodigy in her daughter. Jing-mei says "at first my mother thought I could be a Chinese Shirley Temple. We'd watch Shirley's old movies on TV as though they were training films". Her mother tells "Ni ken"- you watch (Tan 1989, page-715). Her mother even drags Jing-mei to the beauty training school. Here the conflict begins between Jing-mei and her mother. She (mother) says to her daughter "you look like Negro Chinese" (Tan 1989, 715) as if her inherent Chinese background and color is her (Jing-mei) own make; and she has done this intentionally. However, Jing-mei is satisfied with the new hair-cut; and begins to think about her own future fame. She may forget her real identity for some time; and begins to dream that one day she will be "perfect" that her mother will adore her; and she will be like Cinderella stepping from her pumpkin carriage.

Actually, at first, a person should know his/her self and, then, should also confirm to which field he/she may build his/her career. Jing-mei fails to understand her own "self" and, thus, she fails to choose her career field. She thinks that she has a prodigal talent like Shirley Temple that becomes impatient and warns, "If you don't hurry up and get me out of here, I'm disappearing for good" and it also adds "Then you'll always be nothing" (Tan 1989, p. 716). In fact, she (Jing) is "nothing" from the beginning but may seem to pretend to be prodigy like Shirley. Her fascination to be a prodigy is utterly shattered when she looks at herself in the mirror; she sees, "I looked at the reflection, blinking so I could see more clearly. The girl staring back at me was angry, powerful". (Tan 1989, p. 717).The girl staring back does not let Jing-mei to change herself to what she is not fit in. But it is true that Jing-mei sees her true self in the mirror that explains she is nothing but a looser. The girl in the mirror might be angry with Jing-mei, who seems to be betraying her true self. Jing-mei here reflects the character of Henry in The Native Speaker, who is called as being a "false speaker of English" by his wife. He is also considered as being a betrayer, traitor, anti- romantic, strange and so on. His "being" as a Korean; and his "becoming" as an American Korean make him look strange to himself. Jing-mei like Henry also feels strange to herself; and realizing her identity she cries crazily; and tries to scratch out the face reflected in the mirror. She gives up all hope because she comes to know herself in her subjective emotion.

She is individually subjected and, thus plays a given role by inheritance as well as made not socially but individually. Her (given) identity is realized when she cries at her mother "Why don't you like me the way I am? I'm not a genius"(page- Tan 1989, p.719). What she means saying is her rejection to be what Mrs. Woo wants her daughter to be. At the same time, she introduces her mother as "nothing" as well. Indeed, it is called 'self-symbolizing' that her mother reflects on because Mrs. Woo's failure in the past does not stop her making new pursuits. With the identity goal concept, Mrs. Woo actually points her daughter at a non-self-defining goal to achieve. Mrs. Woo believes that her daughter can be whatever her daughter wishes; but in her daughter's case, it is not in her daughter's hand to decide. So, then what does that happen? Mrs. Woo projects her own emotions [....that she still cannot forget her failure] to her daughter forcefully what her daughter looks at it being burdens. If there is American dream, it is there for Jing-mei's mother to decide goals for Jing-mei; not Jing-mei to decide 
for herself. Jing-mei says "If her mother had as much talent as her temper, she would be famous now." (Tan 1989, p. 719). However, both mother and daughter offer a crisis of identity because they both reflect on duel cultures e.g. Chinese and American. Jing-mei's problem is that she cannot cope with her mother's ChineseAmerican temperament because she feels trapped in her hybrid identity.

From the psychoanalytic point of view, it is the matter of "motivation", or if we apply "the theory of instinct" on Jing-mei, we find her in complex situation instinctually. She says, "I'll never be the kind of daughter you want me to be" (Tan 1989, p. 724). She is of another kind, who follows her own mind. Thus, she hovers between the questions e.g. who she is! She is strange like the character of Laura Brown in The Hours, who is a housewife; but notwithstanding she searches for an identity of her life. For an example, she is just living her life for her husband's sake while the readers are confused at certain point: "who is speaking?" When Jing - mei shouts at her mother saying I wish I wasn't your daughter, the readers are pretty confused if she is Jing- mei. Actually, she feels some worms and toads coming outside of her mouth; and if it is observed keenly, we see her certain behavior is really like what she says, "awful side of me that surfaced, at last" (Tan 1989, p. 724) is not prodigy at all.

\section{Conclusion}

To sum up, I want to conclude that a person's subjective emotion is his/her identity. Jing-mei's self determines her own role in her life. Why she cannot come to terms with her mother is nothing but her own complex instinct that promotes her to a level of thinking that she is not genius; or cannot do the best her mother asks for. But it is not clear if she is not a genius, or she never tries to be so. Her mother always tries to bring the best in her daughter; but fails thoroughly in her attempt because Jing-mei comes between the socio-cultural influences of the American dream and her mother's failure. Actually, American dream is in her mother's mind that drives her mad because she believes America is the land where everything may come true. American dream means struggle through which a person can reach his/her goal and, thus, Jing-mei is forced by her mother to try to achieve her goal at least. She wants to bring the best in her daughter. But Jing-mei is tired of coping with the struggle process of the American dream because American dream is a concept, that her agentive reason hardly allows in her soul. On the other hand, Jing-mei's "identity" as being a Chinese girl clings to her throughout her life, she tries to throw it out though. She feels humiliated with her Chinese face; and color that help reduce her strength to a great extent. From my view of the novel, it is summed up that Jing- mei cannot cope with her mother's choice of way because she (Jing) is what she is and that is her own identity; and subjective way of thinking.

\section{E-book:}

\section{References}

[1] Gergen, K. J. (2007). The self: Colonization in psychology and society. Psychology's territories: Historical and contemporary Book: perspectives from different disciplines, 149-167.

[2] Huntley, E. D. (1998). Amy Tan: A Critical Companion. Westport, CT: Greenwood Press.

Book:

[3] Carol Oates, Joyce. (Ed.). (1999). The Oxford Book of American Short Stories. Oxford: Oxford University Press.

\section{Research Working Papers:}

[4] Edmiston, K. D., Brooks, L., \&Shelpelwich, S. Student Loans: Overview and Issues (Update).

\section{Social Genome Project Research}

[5] Sawhill, I., Winship, S., \&Grannis, K. (2012). Pathways to the middle class: Balancing personal and public responsibilities. Washington, DC: Brookings.

Journal:

[6] andBurtless, G. (2013), Coming Apart: The State of White America, 1960-2010, by Charles Murray, New York: Crown Forum/Random House, 2012, 407 pp., \$27.00 hardcover. J. Pol. Anal. Manage., 32: 211-218. doi: 10.1002/pam.21671

[7] Mele,A.(1997).Real self-deception. Behavioral and Brain Sciences, 20, pp 91-136.

\section{Book:}

[8] Mele,A.(2000). Self-deception unmasked. Princeton, NJ: Princeton University Press. 